\title{
Consolidation of cubic and hexagonal boron nitride composites
}

\author{
W. L. Du Frane*, O. Cervantes, G. F. Ellsworth, J. D. Kuntz
}

Lawrence Livermore National Laboratory

In prep. for Diamond and Related Materials

* Correspondence: dufrane2@1lnl.gov, Office +1-925-423-8026, Fax +1-925-422-1360

\begin{abstract}
Consolidating cubic boron nitride $(\mathrm{cBN})$ typically requires either a matrix of metal bearing materials that are undesirable for certain applications, or very high pressures within the cBN phase stability field that are prohibitive to manufacturing size and cost. We present new methodology for consolidating high stiffness $\mathrm{cBN}$ composites within a hexagonal boron nitride (hBN) matrix (15-25 vol\%) with the aid of a binder phase (0-6 vol\%) at moderate pressures ( $0.5-$ $1.0 \mathrm{GPa})$ and temperatures $\left(900-1300{ }^{\circ} \mathrm{C}\right)$. The composites are demonstrated to be highly tailorable with a range of compositions and resulting physical/mechanical properties. Ultrasonic measurements indicate that in some cases these composites have elastic mechanical properties that exceed those of the highest strength steel alloys. Two methods were identified to prevent phase transformation of the metastable $\mathrm{cBN}$ phase into $\mathrm{hBN}$ during consolidation: 1. removal of hydrocarbons, and 2. increased cBN particle size. Lithium tetraborate worked better as a binder than boron oxide, aiding consolidation without enhancing $\mathrm{cBN}$ to $\mathrm{hBN}$ phase transformation kinetics. These powder mixtures consolidated within error of their full theoretical mass densities at $1 \mathrm{GPa}$, and had only slightly lower densities at $0.5 \mathrm{GPa}$. This shows potential for consolidation of these composites into larger parts, in a variety of shapes, at even lower pressures using more conventional manufacturing methods, such as hot-pressing.
\end{abstract}

\section{Introduction}


The cubic and hexagonal structures of boron nitride both have vastly different physical and mechanical properties from one another that are both uniquely valuable for a number of applications. Boron and nitrogen are isoelectronic with carbon, leading to a phase diagram for boron nitride that is analogous to carbon [1-3]. Boron nitride has cubic and hexagonal structures with similar crystal structures and mechanical properties to diamond and graphite respectfully [2]. However, boron nitride has lower chemical reactivity and higher thermostability, which makes it more preferable over diamond and graphite for high temperature applications under oxidizing conditions $[2,3]$.

Hexagonal boron nitride (hBN) has a layered structure, with strong, intra-layer covalent bonding and weak, inter-layer van der Waals bonding. As a result hBN has low overall hardness that allows it to be commonly utilized as a solid medium lubricant, often referred to as 'white graphite', under high temperature and highly oxidizing conditions [3]. hBN is sometimes mixed into ceramics to give them self-lubricating properties; and into oxides, borides, and carbides to increase resistance against thermal shock or corrosion [3]. It is commonly used in experiments as a solid pressure media, because of its effectiveness at transmitting pressure. Boron and nitrogen are low $\mathrm{Z}$ elements making boron nitride transparent to $\mathrm{x}$-ray radiation, so $\mathrm{hBN}$ is also commonly used as a crucible/capsule material in synchrotron studies. With properties similar to graphite, the hexagonal sheets of boron nitride can be disordered to form turbostratic phases, nanotubes, and aerogels [4-6].

Cubic boron nitride $(\mathrm{cBN})$ occurs naturally as a rare mineral named qingsonite that was recently discovered in Tibet as microscopic inclusions inside Cr-rich rocks originating from deep earth [7]. $\mathrm{cBN}$ is a superhard material that is second only to diamond in hardness. Due to its hardness, strong covalent bonding, and stability it is commonly synthesized and used in many 
cutting and grinding applications [2,3]. However, these same properties present significant challenges for sintering $\mathrm{cBN}$ powders into dense, low porosity parts.

There are two commonly used processes for consolidating cBN. The first process transforms $\mathrm{hBN}$ within the $\mathrm{cBN}$ phase stability field, typically requiring very high pressures $(\geq$ $5.8 \mathrm{GPa})$ and temperatures $\left(\geq 1450^{\circ} \mathrm{C}\right)[8]$. These conditions are prohibitive to manufacturing size and cost. Also, cBN by itself is brittle and lacks the fracture toughness required for many commercial applications. Alternatively, $\mathrm{cBN}$ powder is consolidated within a matrix of other metal containing powders to create cermets for cutting tools [9-11]. These metals are potential sources of contamination that are undesirable for some machining procedures. All grinding processes will result in some degree of contamination in the finished product, so the choice and overall purity of grinding media are an important consideration for applications that are sensitive to even ppm or ppb levels [12-15]. Also phase transformation of $\mathrm{cBN}$ to $\mathrm{hBN}$ is a potential challenge when consolidating cBN outside of its stability field [16]. The current methods for consolidating cBN have limitations in size, shape, and potential for contamination.

Here we present the methods we have developed to combine $\mathrm{cBN}$ and $\mathrm{hBN}$ with a small amount of binder $\left(\mathrm{Li}_{2} \mathrm{~B}_{4} \mathrm{O}_{7}\right.$ or $\left.\mathrm{B}_{2} \mathrm{O}_{3}\right)$ to create versatile, fully-dense, high purity boron nitride ceramics that utilize the unique properties of both BN phases for several advantages over existing $\mathrm{BN}$ ceramics and cermets. The presence of $\mathrm{hBN}$ lubricates impinging grain contacts during consolidation allowing for fully dense, high cBN content composites to be created at relatively lower pressures and temperatures in comparison to other methods. Despite the presence of $\mathrm{hBN}$, the composites have high elastic stiffness that in some cases exceeds even the strongest steel alloys. 
There are several potential applications that could benefit from utilization of $\mathrm{cBN} / \mathrm{hBN}$ composites. These cBN composites can be machined, ground, or potentially pressed into specific shapes to match the needs of a variety of grinding applications. The presence of hBN would give the grinding tools self-lubricating properties [3], and could be used in grinding or polishing in applications where metal contamination is unacceptable [12-15]. Finally, there is a substantial difference between the densities of the two main components, $\mathrm{hBN}\left(2.1 \mathrm{~g} / \mathrm{cm}^{3}\right)$ and $\mathrm{cBN}(3.45$ $\mathrm{g} / \mathrm{cm}^{3}$ ), that allows mixtures of these phases to be tailored to a wide range of densities to match specific needs. Boron nitride crucibles have been used as crucibles in studies on metal sulfide systems [17, 18], and serve as highly effective reducing agents [19]. These ceramics are highly transparent to $\mathrm{x}$-ray radiation because they are composed entirely of low $\mathrm{Z}$ elements $(\mathrm{B}, \mathrm{N}, \mathrm{Li}$, O), making them potentially useful materials as transparent crucibles or anvils in synchrotron studies $[20,21]$. The densities of $\mathrm{cBN} / \mathrm{hBN}$ composites could be tailor-matched to the materials of interest to reduce reflections during radiographic or tomographic x-ray imaging.

\section{Experimental techniques}

Samples were composed of varying proportions of cBN (66-80 vol\%), hBN (15-25 vol\%) and binder (0-6 vol\%). Two types of materials were explored for use as a binder and consolidation aid: lithium tetraborate $-\mathrm{Li}_{2} \mathrm{~B}_{4} \mathrm{O}_{7}$ (LTB) with a melting point of $930{ }^{\circ} \mathrm{C}$ and boron oxide $-\mathrm{B}_{2} \mathrm{O}_{3}$ with a melting point of $450{ }^{\circ} \mathrm{C}$ at $1 \mathrm{~atm}$. Most runs used LTB (Alfa Aesar), one run used boron oxide $\mathrm{B}_{2} \mathrm{O}_{3}$ (Alfa Aesar), and several runs were performed without any binder phase present. The hBN (Alfa Aesar) was -325 mesh powder $(<44 \mu \mathrm{m})$, and the LTB (Alfa Aesar) was -22 mesh powder $(<710 \mu \mathrm{m})$. Several different size distributions of $\mathrm{cBN}$ were used by mixing sieved particle sizes of 0-2, 30-40 (Diamond Innovations), or 2-4 $\mu \mathrm{m}$ (Engis). Samples compositions are listed in Table 1. All powders were ground and mixed together for 30 minutes 
duration using a Retsch RM100 fitted with an agate mortar and a spring loaded pestle set to intermediate force.

The piston cylinder press technique has been proven useful for consolidation of both high hardness and metastable materials in previous studies [22]. Powder mixtures were consolidated using a piston cylinder press at pressures of either 0.5 or $1.0 \mathrm{GPa}$ and temperatures between 900 $1300{ }^{\circ} \mathrm{C}$. Approximately $1.2 \mathrm{~g}$ of these powder mixtures were loaded into fired pyrophyllite capsules (Rockland Research) by tamping down the powder with a drill blank. The loaded capsules were placed into an assembly with an alumina sheathed type $\mathrm{C}$ thermocouple, $\mathrm{MgO}$ rod that provided electrical insulation, a graphite furnace, a Pyrex sleeve that provided thermal insulation, and a salt sleeve that allowed effective transmission of pressure at the target run temperatures (Fig. 1). The assembly is inserted into a pressure plate with a carbide core that is end-loaded to increase its strength. A piston is driven by a separate ram to generate sample pressure. Samples were heated and cooled at a rate of $100{ }^{\circ} \mathrm{C} / \mathrm{min}$ to/from target temperatures where samples dwelled for 30 min (Fig. 2).

Phase transformation of $\mathrm{cBN}$ to $\mathrm{hBN}$ was an issue that affected our preliminary runs; however, methods to prevent this reaction from occurring were identified and incorporated into the procedure used in later runs. For our initial runs (referred to hereafter as 'method 1'), assemblies loaded with sample powders were placed into a drying oven at $\sim 105^{\circ} \mathrm{C}$ for durations of 20 min for runs 1-3 and 15-30 hours for runs 4-10. Based on our observations from method 1 runs, two procedural changes were made for subsequent runs 13-58 (referred to hereafter as 'method 2'). First we eliminated the use of $\mathrm{cBN}$ powder that was $<2 \mu \mathrm{m}$ in size from sample powder mixtures. Second, capsules loaded with sample powder mixtures and adjacent $\mathrm{MgO}$ and 
graphite assembly parts were then fired at $700{ }^{\circ} \mathrm{C}$ under $250 \mathrm{sccm}$ of flowing $\mathrm{N}_{2}$ gas for 4 hours, and promptly transferred to the drying oven for $<8$ hours prior to experiments.

High precision density measurements are ultimately the best way to confirm that full densification of powder mixtures was achieved while maintaining the same composition throughout experiments. Consolidated samples were machined into cylinders to simplify their geometries and enable accurate measurements. To calculate the geometric volume and densities, diameter and thickness of the cylindrical samples were measured by calibers with $25 \mu \mathrm{m}$ accuracy, and weight was measured with $0.1 \mathrm{mg}$ accuracy. These errors were propagated to calculate sample density errors. Geometric densities of consolidated samples were compared to the theoretical mass densities of the starting powder mixtures.

\section{Analytical techniques}

Thermogravimetric analysis (TGA) and differential scanning calorimetry (DSC) were performed using a Netzch TG 449 F1 Jupiter with a silica carbide furnace to quantify the amount of volatile materials in powders. The instrument has $2.5 \times 10^{-8} \mathrm{~g}$ TGA resolution. Approximately $100 \mathrm{mg}$ of each individual constituent powder used in this study was heated at rate of $20^{\circ} \mathrm{C} / \mathrm{min}$ under $20 \mathrm{sccm}$ of flowing $\mathrm{N}_{2}$ gas to a temperature of $1500{ }^{\circ} \mathrm{C}$ for the $\mathrm{hBN}$ and $\mathrm{cBN}$ powders in $\mathrm{Al}_{2} \mathrm{O}_{3}$ crucibles, and to $1000{ }^{\circ} \mathrm{C}$ for the LTB powders in $\mathrm{Pt}_{90} \mathrm{Rd}_{10}$ crucibles to prevent sample/crucible reactions. Crucibles were burned out without powder beforehand using conditions identical to measurements. Powders were rerun using the same conditions to subtract background signals for TGA/DSC data. Powders were kept under continuous nitrogen flow between the first and second runs without exposing samples to air.

Scanning electron microscopy (SEM) was performed to verify grain size distribution, and purity of unmixed and mixed powders using an FEI XL30 S-FEG. Samples were viewed via 
Backscatter Electrons utilizing a solid state backscatter detector. The parameters used for imaging were: $20 \mathrm{kV}$ voltage, $1.3 \mathrm{~nm}$ spot size, $\sim 148 \mathrm{pA}$ beam current, $1.4 \mu \mathrm{m}$ depth.

$\mathrm{X}$-ray diffraction (XRD) was performed before and after consolidation to verify composition using a Bruker AXS D8 ADVANCE X-ray diffractometer equipped with a LynxEye 1-dimentional linear Si strip detector. Samples were scanned from $2 \theta$ between $20-80^{\circ}$. The step scan parameters were $0.02^{\circ}$ step and 1 second counting time per step with a $6 \mathrm{~mm}$ variable divergence slit and a $0.5^{\circ}$ antiscatter slit. The sample was $\mathrm{x}$-rayed with $\mathrm{Ni}$-filter $\mathrm{Cu}$ radiation from a sealed tube operated at $40 \mathrm{kV}$ and $40 \mathrm{~mA}$. X-ray reference material (Bruker corundum standard) was analyzed before and after the samples to ensure goniometer alignment. No peak shift was observed in the reference material. Sample compositions were determined using the Rietveld refinement method, with $\pm \sim 5 \%$ error [23].

Mechanical properties of consolidated samples were assessed by performing ultrasonic measurements with both 'time of flight' (TOF) and 'resonant spectral ultrasound' (RUS) methods. For TOF, one transducer was placed against samples producing ultrasonic waves and detecting their return echoes as they traversed to the other end of the sample and back. Velocity $(\mathrm{V})$ is equal to twice the thickness (L) of the sample divided by travel time $t$ :

$$
V=\frac{2 L}{t} .
$$

Both longitudinal and shear wave transducers were used to measure their respective velocities. Shear wave velocities were measured in two orthogonal directions to verify that samples could be approximated as isotropic mediums for the purpose of solving the elastic tensor matrix. This allows ultrasonic sound velocity measurements to be used to calculate Young's modulus $(\mathbf{E})$, bulk modulus (B), shear modulus (S), and Poisson's ratio (v) using the following equations:

$$
\mathbf{E}=\rho \mathrm{v}_{\mathrm{s}}{ }^{2}\left(3 \mathrm{v}_{\mathrm{p}}{ }^{2}-4 \mathrm{v}_{\mathrm{s}}{ }^{2}\right) /\left(\mathrm{v}_{\mathrm{p}}{ }^{2}-\mathrm{v}_{\mathrm{s}}{ }^{2}\right)
$$




$$
\begin{aligned}
& \mathbf{B}=\rho\left(\mathrm{v}_{\mathrm{p}}{ }^{2}-4 \mathrm{v}_{\mathrm{s}}{ }^{2} / 3\right) \\
& \mathbf{S}=\rho \mathrm{v}_{\mathrm{p}}{ }^{2} \\
& v=\left(1-2\left(\mathrm{v}_{\mathrm{s}} / \mathrm{v}_{\mathrm{p}}\right)^{2}\right) /\left(2-2\left(\mathrm{v}_{\mathrm{s}} / \mathrm{v}_{\mathrm{p}}\right)^{2}\right)
\end{aligned}
$$

where $\rho$ is density, $V_{p}$ is longitudinal wave velocity, and $V_{s}$ is shear wave velocities. More complicated return signals were processed using a cross-correlation technique to extract individual pulse arrival times [24]. Measurement resolution of thickness $( \pm 50 \mu \mathrm{m})$ and time $( \pm 1$ ns) were propagated to determine the wave velocity errors that had an average value of $0.128 \%$, showing high confidence in the TOF measurements. This combined with density errors were propagated to determine errors for $\mathbf{E}, \mathbf{B}, \mathbf{S}$, and $v$.

Precise TOF measurements were not possible for samples with higher thickness than diameter, because faster longitudinal waves interfere with detection of the secondary arrival of slower shear waves. Resonance ultrasound spectroscopy (RUS) method was used for samples with geometries that could not be measured reliably with the TOF method. The technique measures the frequencies corresponding to elastic resonance and free oscillation for a sample of known dimensions. RUS data was fitted with root mean square (RMS) fits to a Breit-Wigner model to obtain elastic properties using commercial software $[25,26]$. General errors were on the order of $0.5 \%$ for $\mathbf{E}, 0.02 \%$ for $\mathbf{S}$, and $2 \%$ for $\mathbf{B}$ and $v$ based on typical $0.5-1 \%$ RMS fits of the RUS data [27].

\section{Results}

\subsection{Powder Characterization}

The TGA data indicates that the individual, constituent powders used in this study had only small amounts of volatiles present $(\leq 0.5 \mathrm{wt} \%)$ (Fig. 3A). Increasingly more weight loss occurred for increasingly finer grain $\mathrm{cBN}$ powders, with up to $\sim 1 \mathrm{wt} \%$ lost from $0-0.5 \mu \mathrm{m}$ 
powder that was not used in sample mixtures, whereas cBN powders $>2 \mu \mathrm{m}$ exhibited less than $0.2 \mathrm{wt} \%$ loss. cBN powder with $0-0.5 \mu \mathrm{m}$ sizes exhibited two distinct weight loss events that coincided with initially endothermic and then exothermic signals (Fig. 3B). The endothermic signal and weight loss at $\sim 100{ }^{\circ} \mathrm{C}$ is consistent with boil off of water. The exothermic signal was exhibited in all powders, with maximum magnitude of the signal increasing and occurring at lower temperatures for increasingly finer $\mathrm{cBN}$ powder sizes. TGA data for the $\mathrm{hBN}$ indicated $\sim 0.5 \mathrm{wt} \%$ loss, which is larger than cBN of comparable size. Layered structures, like $\mathrm{hBN}$, are typically capable of hosting large amounts of water and other volatiles through intercalation of small molecule contaminates between the hexagonal layers of the crystal structure. The $\mathrm{hBN}$ also had substantial weight loss above $\sim 450^{\circ} \mathrm{C}$, which corresponds to the melting temperature of $\mathrm{B}_{2} \mathrm{O}_{3}$, suggesting that it is has some oxidation as received. DSC data for the $h B N$ indicated a similar endothermic event at $\sim 100{ }^{\circ} \mathrm{C}$, as well as two exothermic events with maximum signals at $\sim 1000$ and $\sim 1300{ }^{\circ} \mathrm{C}$. DSC data for the LTB showed large endothermic signals in the initial and repeated measurements that verified the manufacturers reported melting point of $930^{\circ} \mathrm{C}$ (Fig. 3C). There was also a large exothermic signal during the rerun that did not occur in initial run, which results in what falsely appears as an endothermic signal at $\sim 600^{\circ} \mathrm{C}$ in the subtracted data. This exothermic signal that occurred during the rerun was likely the result of recrystallization of the LTB. The LTB sample appeared to be glassy after recovery from the TGA/DSC experiment. SEM analyses were performed on sample powders before and after mixing to verify their purity, size, and distribution. SEM images of individual, unmixed cBN powders had narrow grain size distributions consistent with those specified by their manufacturers. After samples powders were mixed and ground by the mortar and pestle, courser $\mathrm{cBN}$ grains were homogeneously coated with finer grains of cBN, hBN, and LTB (Fig. 4A). Particle sizes of LTB 
and $\mathrm{hBN}$ reduced to sub-micron diameters, while both fine and course grained $\mathrm{cBN}$ remained angular with little to no size change during grinding.

XRD analyses were performed on sample powders before and after mixing to verify their composition had not changed. No other phases were detected in XRD analyses performed on the individual starting powders used in sample mixtures. Compositions of sample powder mixtures calculated from XRD spectra were in good agreement with those calculated by weight.

\subsection{Consolidation Results}

Consolidated samples were recovered after piston cylinder runs, and machined into cylinders using several different methods and cutting tools (Fig. 5). Samples were ground and polished using a lapping fixture to ensure surfaces were parallel within \pm 0.001 '. Samples were ground flat from the top and bottom directions along their cylindrical axes using a polycrystalline diamond (PCD) grinding wheel, and finished with $15 \mu \mathrm{m}$ diamond slurry. This allowed samples to be pressure plated on a lathe where samples were turned down to cylinders with rotational speeds between 125-1500 rpm and feed rates between 0.001-0.005" per revolution using a variety of cutting tools. At high speeds the composites behaved similarly to a grinder, creating flats on the cutting edge of the inserts. Tungsten carbide tools performed very poorly at cutting samples, with tool edges wearing rapidly. PCD tools wore down at lower rates. The T-DIA tool from Tungaloy was found to be the most successful for cutting samples. Sample thicknesses and diameters varied after machining, but average values were $4 \mathrm{~mm}$ and $7 \mathrm{~mm}$ respectively. To further test machinability, samples PC1 and PC6 had holes drilled into them using carbide bits on a drill-press.

SEM images of polished surfaces of samples PC19, and PC40 indicated that mixtures stayed homogenous throughout consolidation (Fig. 4B-D). Images at magnification 1 show that 
course $30-40 \mu \mathrm{m}$ cBN grains are embedded within a matrix of finer particles and remain intact and angular. Images at magnification 2 of the matrix show that the $2-4 \mu \mathrm{m} c B N$ grains are coated with the LTB and hBN, which are no longer distinguishable as particles Some surface porosity is observed in the fine-grained matrix of polished surfaces, but images of the freshly fractured surface of sample PC19 (Fig. 4B) indicates that the samples are fully densified (Fig. 4C and 4D). This porosity is likely caused by grain pullout of the harder $\mathrm{cBN}$ from the softer $\mathrm{hBN}$ and LTB it is embedded in. The images of the freshly fractured surface also show transgranular fracture in the courser grains, which suggests they are strongly fused within the fine-grained matrix of the composites.

XRD spectra were collected on consolidated samples to evaluate whether or not composition changed during runs. The LTB no longer exhibited diffraction peaks. We assume that this was not an indication that the LTB changed in concentration, but instead changed in crystallinity and texture through a combined process of melting, redistributing, and quenching that is consistent with SEM Images (Fig. 4). TGA/DSC experiments confirmed that LTB melts and quenches as a clear, glassy phase. The LTB would not have escaped the capsule, because piston cylinder assemblies are designed to trap phases inside the crucibles using heavily deformable materials (i.e. $\mathrm{NaCl}$, Pyrex, crushable ceramics, and steel) in combination with large over-pressures (e.g. Du Frane et al. [28, 29] has used the piston cylinder technique to routinely preserve and recover liquid water from experiments at $950{ }^{\circ} \mathrm{C}$ for 48 hours). XRD analyses on method 1 samples indicated that their $\mathrm{cBN}$ concentrations decreased and $\mathrm{hBN}$ concentrations increased by variable amounts (Fig 6A, Table 1). These results imply that significant phase transformation of cBN to hBN occurred during runs prepared by method 1 (Fig. 6A). Samples containing fine grained $0-2 \mu \mathrm{m} \mathrm{cBN}$, and/or binder phase (LTB or $\mathrm{B}_{2} \mathrm{O}_{3}$ ) exhibited the most cBN 
to hBN phase transformation (Table 1). In contrast, samples consolidated by method 2 did not exhibit significant $\mathrm{cBN}$ to $\mathrm{hBN}$ phase transformation (Fig 6B, Table 1).

The phase transformation reaction changes the overall composition and the theoretical mass density (TMD) of the samples. Starting TMD values were calculated from the measured weights of the individual powders used in sample mixtures. Consolidated samples run by method 1 resulted in densities that were significantly further from their starting TMD relative to those run by method 2 (Fig. 7A, 7C). To further evaluate possible causes for this, XRD was used to determine whether or not sample compositions had changed significantly during runs. Changes in the $\mathrm{cBN}: \mathrm{hBN}$ ratio were significantly larger than errors for Rietveld refinement method $( \pm$ $\sim 5 \%$ ), confirming that $\mathrm{cBN}$ to $\mathrm{hBN}$ phase transformation was an issue affecting the method 1 runs. Ending TMD values $\left( \pm \sim 0.07 \mathrm{~g} / \mathrm{cm}^{3}\right.$ error) were recalculated by adjusting the ratio of $\mathrm{cBN}: \mathrm{hBN}$ to the post-run values measured by XRD. All samples resulted in densities that were fairly close to their ending TMD values, which indicates that all samples had little $(<5 \%)$ to no remaining porosity (Table 1) (Fig. 7B and 7D).

Using the method 2 procedure, with the modifications developed to prevent the $\mathrm{cBN}$ to $\mathrm{hBN}$ phase transformation, a series of runs (15-58) were conducted with at various pressure/temperature conditions on 4 different sample compositions with cBN/hBN/LTB in the following volume percentages: 70/25/5, 75/20/5, 75/25/0, 80/15/5 (Table 1). The cBN size distribution used in these runs was a 4:1 ratio of the $30-40 \mu \mathrm{m}: 2-4 \mu \mathrm{m}$. The approximately 1 order of magnitude difference in $\mathrm{cBN}$ sizes was chosen so that an idealized packing arrangement could be achieved, with the smaller grains filling the larger pore space of courser grains.

Consolidation runs resulted in sample densities that were on average within $2 \%$ of starting TMD values (Fig. 8). At $1 \mathrm{GPa}$ and $1000{ }^{\circ} \mathrm{C}$, sample densities for all 4 compositions 
were within error of their starting TMDs. The geometric densities we measured for runs at 0.5 GPa were only slightly lower than those run at $1.0 \mathrm{GPa}$ at comparable temperatures (Fig. 8).Temperature did not have a large effect, particularly for the 70/25/5 and 75/20/5 compositions. At $1 \mathrm{GPa}$, sample densities were slightly lower at 900 and $1300{ }^{\circ} \mathrm{C}$ for all compositions consolidated.

Ultrasonic methods were used to assess the mechanical properties of consolidated samples (Table 1). For TOF measurements, equations 2-5 were used to determine Young's, Bulk, Shear moduli, and Poisson's ratio. Poisson's ratio obtained using the TOF method had large overall scatter, but outliers indicated that shear-wave velocity measurements were not reliable. This is mostly an issue for samples that had thicknesses greater than their diameters. The TOF measurement of Poisson's ratio for PC19 was much higher in magnitude than all the other samples, and a few other samples had negative values for Poison's ratio measured by the TOF method, which is not physically possible. These outlying samples were re-measured using the RUS method to obtain more accurate values.

Young's, Bulk, and Shear moduli measured for these composites trended upward with increasing overall density (Fig. 9). It is typical for elastic moduli to decrease with increased porosity. The elastic moduli also decrease with increasing hBN content in the composites (Fig. 10). Samples consolidated at $0.5 \mathrm{GPa}$ had slightly lower density (and likely higher porosity) (Fig. 8). Otherwise, the trend was similar to that of samples consolidated at $1.0 \mathrm{GPa}$, suggesting that consolidation pressure does not have a direct effect on mechanical properties.

\section{Discussion}

Fully dense composites were able to be consolidated with a range of cBN contents (20-80 vol\% post-run) and densities $\left(2.45-3.24 \mathrm{~g} / \mathrm{cm}^{3}\right)$ at $1 \mathrm{GPa}$ (Fig. 7). These results demonstrate that 
cBN-hBN composites are highly tunable. The mechanical properties of these composites are also highly variable (Figs. 9 and 10), and could be tailored to meet the specific needs of numerous applications.

Phase transformation of the metastable $\mathrm{cBN}$ phase to the stable $\mathrm{hBN}$ phase reduced sample densities in our preliminary runs (method 1), similar to previous workers [16]. Impurities and $\mathrm{cBN}$ surface area are two factors that are demonstrated to increase $\mathrm{cBN}$ to hBN phase transformation [30]. The extent of this reaction was highest for method 1 samples that contained very fine grain $\mathrm{cBN}$ powders or binder (Table 1, Figs. 7A and 7B). Finer grained cBN has higher surface area to volume ratio, and therefore more overall grain boundary area available per volume for $\mathrm{hBN}$ nucleation to occur. TGA/DSC indicated that $\mathrm{cBN}$ powders contained larger amounts of volatile materials for increasingly finer grain size, and the hBN powder contained $\sim 0.5 \mathrm{wt} \%$. The majority of $\mathrm{H}_{2} \mathrm{O} /$ volatile loss occurs below $700{ }^{\circ} \mathrm{C}$, the temperature that was used to bake out powders before consolidation (Fig. 3). Drying these powders at $105{ }^{\circ} \mathrm{C}$ for durations up to $30 \mathrm{hrs,}$ was insufficient for preventing $\mathrm{cBN}$ to $\mathrm{hBN}$ phase transformation during consolidation. It is not surprising that volatiles affect the $\mathrm{cBN}$ to $\mathrm{hBN}$ phase transformation kinetics, it was not expected that they would be this sensitive to volatiles. Also the two binder phases used, $\mathrm{B}_{2} \mathrm{O}_{3}$ and LTB, are both hygroscopic.

There are several possible ways that $\mathrm{H}_{2} \mathrm{O}$ and other volatiles could reduce the densities of consolidated parts. Experiments by Sachdev et al. have verified that $\mathrm{B}_{2} \mathrm{O}_{3}$ lowers conversion temperature to as low as $900{ }^{\circ} \mathrm{C}$ for submicron cBN with $\mathrm{hBN}$ forming with different textures on cBN crystal surfaces, noting that $\mathrm{B}_{2} \mathrm{O}_{3}$ reduces the vapor pressure of hBN [30]. This is consistent with the low density measured for sample PC9 that contained $\mathrm{B}_{2} \mathrm{O}_{3}$ as a sintering aid, and suggests that the LTB is likely a better material to use. Sachdev et al. proposed two mechanisms 
for the $\mathrm{cBN}$ to $\mathrm{hBN}$ reaction: 1) a solid-state mechanism from $\mathrm{cBN}$ to $\mathrm{hBN}$, with a possible intermediate formation of rhombohedral hBN; and 2) a gas phase mechanism requiring volatiles to be present. The presence of other volatiles, such as water or hydrocarbon, may be helping form $\mathrm{B}_{2} \mathrm{O}_{3}$ in samples. For example, $\mathrm{H}_{2} \mathrm{O}$ may react with $\mathrm{BN}$ to form $\mathrm{NH}_{3}$ and $\mathrm{B}_{2} \mathrm{O}_{3}$ by the following reaction:

$$
3 \mathrm{H}_{2} \mathrm{O}+2 \mathrm{BN} \leftrightarrow 2 \mathrm{NH}_{3}+\mathrm{B}_{2} \mathrm{O}_{3}
$$

Hydrogen itself may also be problematic. It is known to catalyze the reversed reaction of $\mathrm{hBN}$ to $\mathrm{cBN}$, with the amounts retained in 'dry' powders alone reducing transformation pressure from 10 to $5.5 \mathrm{GPa}$ [31]. For example, the presence of hydrogen in amounts as low as $\sim 100$ part per million by weight is known to substantially increase the transformation kinetics of other metastable phases by alleviating stress associated with volume changes through hydrolytic weakening [28]. Finally, pores may be prevented from closing completely during consolidation if substantial quantities of $\mathrm{H}_{2} \mathrm{O}$ fluids are trapped inside samples.

To prevent $\mathrm{cBN}$ to $\mathrm{hBN}$ phase transformation, we made two modifications to our experimental procedure. First, we eliminated the use of $0-2 \mu \mathrm{m} c B N$ to reduce the amounts of volatiles present (Fig. 3) and also to reduce the grain boundary area per volume where hBN nucleation may be occurring. Second, we fired samples (and adjacent assembly pieces) at $1 \mathrm{~atm}$ and $700{ }^{\circ} \mathrm{C}$ under $250 \mathrm{sccm}$ of flowing $\mathrm{N}_{2}$ gas for 4 hours to eliminate the majority of hydrogen, and other volatiles, present in powders. It appears to be critical to burnout powders out at a temperature that is sufficient to melt and volatize any $\mathrm{B}_{2} \mathrm{O}_{3}$ that might be present. This new procedure (method 2) successfully prevented $\mathrm{cBN}$ to $\mathrm{hBN}$ phase transformation during consolidation (Fig. 7D). It also verified that LTB can be used as a binder without contributing significantly as a flux for the $\mathrm{cBN}$ to $\mathrm{hBN}$ phase transformation. This enabled us to control 
composition of cBN/hBN/LTB composites, and focus our efforts towards determining the ideal pressure/temperature conditions for consistent consolidation.

Using our improved methods to prevent $\mathrm{cBN}$ to $\mathrm{hBN}$ phase transformation, four cBN/hBN/LTB mixtures $(70 / 25 / 5,75 / 20 / 5,75 / 25 / 0,80 / 15 / 5$ by vol\%) were consolidated to densities within error of their starting TMD values at $1 \mathrm{GPa}$ and $1000{ }^{\circ} \mathrm{C}$ (Fig. 8). This confirms that all 4 of these compositions were fully consolidated with little or no porosity remaining. This also confirms there was no significant $\mathrm{cBN}$ to $\mathrm{hBN}$ phase transformation or LTB loss occurred during consolidation, because either occurrence would have resulted in lower part densities. Temperature only had small effect on the resulting densities samples, suggesting that the consolidation is somewhat overdriven at these pressures. Samples had slightly lower density at the highest temperature of $1300{ }^{\circ} \mathrm{C}$. This is likely to be the result of $\mathrm{cBN}$ to $\mathrm{hBN}$ phase transformation that was too small a change to be detected by XRD. The kinetics of the cBN to $\mathrm{hBN}$ phase transformation is expected to be a thermally driven process due to the large amount of energy needed to break the strong covalent bonds of the $\mathrm{cBN}$ structure. Conversely, the slightly lower sample densities at $900{ }^{\circ} \mathrm{C}$ are likely caused by a small amount of porosity rather than by $\mathrm{cBN}$ to $\mathrm{hBN}$ phase transformation. This temperature is below the melting point for the LTB, which would reduce its effectiveness as a sintering aid in these runs. There was only a slight decrease $(\sim 5 \%)$ in the overall part densities pressed at $0.5 \mathrm{GPa}$ compared to those at 1.0 GPa. This is a promising result for the possibility of consolidating these ceramic composites at even lower pressures by further optimizing grain-size, phase distribution, and composition.

Ultrasonic measurements indicated that elastic moduli of the composites were very high (Table 1). Some samples exceeded high-strength steel alloys, which range in value with $\mathbf{E}$ between 136 to $218 \mathrm{GPa}, \mathbf{B}$ between 111 to 156, and $\mathbf{S}$ between 41-82 GPa [32]. Samples with 
the highest overall elastic stiffness had highest densities and lowest hBN contents. Excess porosity or $\mathrm{hBN}$ in composites likely aids disaggregation, weakening the overall stiffness of the composites. The pressure of consolidation $(0.5$ or $1.0 \mathrm{GPa})$ had a slight effect on the resulting density of the composites, likely due to slight increase in porosity, but otherwise did not affect mechanical properties. All samples in this study were durable enough to be machined, including the lowest density parts that are expected to be slightly more fragile. Machining the densest samples proved to be challenging, rapidly wearing both cutting tools and grinding surfaces. Tungsten carbide essentially was unable to cut these boron nitride composites. PCD tools were able to cut and grind the samples, but their surfaces wore down rapidly. This is a promising indication that these composites may be durable enough to be utilized as relatively low cost grinding tools in applications where high purity boron nitride is preferred. All composites in this study, including samples with cBN contents as low as 20 vol\% (e.g. sample PC6), were durable enough to be machined. Future experiments will be conducted to attempt consolidation of $\mathrm{cBN} / \mathrm{hBN} / \mathrm{LTB}$ mixtures into larger parts at even lower pressures $(<0.2 \mathrm{GPa})$, and therefore enable larger sample sizes. Larger samples will also enable more extensive testing of mechanical properties, such as compressive and flexural strength, to better assess the potential of these composites for grinding and other applications.

The composites are surprisingly stiff considering they contain a substantial amount of $\mathrm{hBN}(15-25 \mathrm{vol} \%)$, a material that is relatively very weak. Transgranular fractures were observed in course cBN grains of a freshly fractured sample surface (Fig. 4B), which suggests these grains are strongly fused to the matrix of fine grained materials. Despite our successful efforts to inhibit significant amounts of $\mathrm{cBN}$ to $\mathrm{hBN}$ phase transformation during runs, nucleation of $\mathrm{hBN}$ is still likely to occur on cBN grain surfaces. Also the $\mathrm{hBN}$ grains in the starting powder mixtures are 
expected to undergo heavy deformation and recrystallization during consolidation due to the high sheer stresses imposed by impinging cBN grain contacts. Although the $\mathrm{hBN}$ lubricates cBN grain boundaries initially, it might ultimately fuse the cBN together if it grows coherently onto the surfaces of cBN grains. We plan to perform future analyses using transmission electron microscopy to examine this to help determine whether or not hBN recrystallization fuses cBN surfaces, contributing to the high overall stiffness of these composites.

\section{Conclusions}

New techniques for consolidating mixed phase boron nitride in variable compositions at relatively low pressures $(0.5-1.0 \mathrm{GPa})$ and temperatures $\left(900-1300^{\circ} \mathrm{C}\right)$ were presented. Several methods were identified to prevent phase transformation of the $\mathrm{cBN}$ to $\mathrm{hBN}$ that included: 1) limiting particle sizes to $\geq 2 \mu \mathrm{m}$ and 2) firing the sample powders with adjacent assembly parts to $700{ }^{\circ} \mathrm{C}$ in flowing $\mathrm{N}_{2}$ gas. Without volatiles present, LTB acted as a binder and consolidation aid, without causing significant $\mathrm{cBN}$ to $\mathrm{hBN}$ phase transformation. Alternatively, the presence of $\mathrm{B}_{2} \mathrm{O}_{3}$ in samples seems to be problematic. The combined strategy of limiting the amounts of volatiles present and surface area available for nucleation was successful at preserving the metastable $\mathrm{cBN}$ phase under the ranges of conditions that were examined in this study.

Powder mixtures with variable compositions of 70-80 vol\% cBN, 15-25 vol\% $\mathrm{hBN}$, and 0-5 vol\% LTB powder mixtures were pressed to densities within error of their starting TMD values. This demonstrates that the compositions of these mixed phase BN ceramics are highly tunable. Generally, the highest part densities for these compositions were able to be achieved at $1 \mathrm{GPa}$ and $1000^{\circ} \mathrm{C}$. A small amount of $\mathrm{cBN}$ to $\mathrm{hBN}$ phase transformation is likely to have 
occurred at the highest temperature of $1300^{\circ} \mathrm{C}$, and small amount of porosity likely remained in samples at the lowest temperature of $900{ }^{\circ} \mathrm{C}$.

The densest composites with lowest hBN contents had elastic moduli that exceeded even those of the highest strength steel alloys. Halving pressure from 1.0 to $0.5 \mathrm{GPa}$ resulted in only slight decreases in sample densities, but otherwise had no direct effect mechanical properties. This demonstrates great potential for possible consolidation of these powder mixtures into strong, high density composites at even lower pressures.

\section{Acknowledgements}

We thank Professor Emeritus Zuhair Munir (U.C. Davis) for discussions and comments that help to greatly improve this manuscript. We thank Harris Mason and Art 'Colorado Cowboy' Neslon for their helpful comments and discussion, Rick Ryerson for his comments and assistance with operating the piston cylinder press; Sarah Roberts for assistance with XRD; Cheng Saw for performing XRD analysis; Ed Sedillo for performing SEM imaging; Brian Fix and Karl Fisher for performing ultrasonic measurements and calculations; Ernie Young, Francisco Yepiz, and Christian Oda for sample machining (LLNL). This work was performed under the auspices of the U.S. Department of Energy by Lawrence Livermore National Laboratory under Contract DE-AC52-07NA27344.

\section{References}

[1] S. Hu, J. Yang, Y. Dong, S. Cao, and J. Liu, Prediction of formation of cubic boron nitride by construction of temperature-pressure phase diagram at the nanoscale, J. Solid State Chem. 184 (2011)1598-1602.

[2] L. Vel, G. Demazeau, and J. Etourneau, Cubic boron nitride: synthesis, physicochemical properties and applications, Mater. Sci. Eng. B 10:2 (1991) 149-166. 
[3] R. Haubner, M. Wilhelm, R. Weissenbacher , and B. Lux, Boron nitrides - properties, synthesis and applications, Struct. Bond. 102 (2002) 1-45.

[4] M. Gasgnier, H. Szwarc, and A. Ronez, Low-energy ball-milling: Transformations of boron nitride powders. Crystallographic and chemical characterizations, J. Mater. Sci. 35 (2000) 3003-3009.

[5] Y. Chen, J.F. Gerald, J.S. Williams, and S. Bulcock, Synthesis of boron nitride nanotubes at low temperatures using reactive ball milling, Chem. Phys. Lett. 299 (1999) 260-264.

[6] M. Rousseas, A.P. Goldstein, W. Mickelson, M.A. Worsley, L. Woo, and A. Zettl, Synthesis of highly crystalline sp2-bonded boron nitride aerogels, ACS Nano 7:10 (2013) $8540-8546$.

[7] L.F. Dobrzhinetskaya, R. Wirth, J. Yang, H.W. Green, I.D. Hutcheon, P.K. Weber and E.S. Grew. Qingsongite, IMA 2013-030. CNMNC Newsletter No. 16, August 2013, p. 2708; Mineralogical Magazine 77 (2013) 2695-2709.

[8] M.M. Bindal, R.K. Nayar, S.K. Singhal, A. Dhar, and R. Chopra, high pressure sintering of boron nitride, J. Mater. Sci. 21 (1986) 4347-4351.

[9] S.K. Singhal, and B.P. Singh, Sintering of cubic boron nitride under high pressures and temperature in the presence of boron carbide as the binding material, Indian J. Eng. Mater. Sci. 12 (2005) 325-330.

[10] M. Hotta, and T. Goto, WCCo/cBN composites produced by pulse plasma sintering method, J. Ceram. Soc. Japan 118:2 (2010) 137-140.

[11] M. Rosinski, and A. Michalski, WCCo/cBN composites produced by pulse plasma sintering method, J. Mater. Sci. 47 (2012) 7064-7071. 
[12] G. Thompson, and D.C. Bankson, Sample contamination from grinding and sieving determined by emission spectrometry, Appl. Spectrosc. 24:2 (1970) 210-219,

[13] R. Van Grieken, R. Van De Velde, and H. Robberecht, Sample contamination from a commercial grinding unit, Analytica Chimica Acta, 118 (1980) 137-143.

[14] C.J. Hickson and S.J. Juras, Sample contamination by grinding, Canadian Mineralogist, 24 (1986) 585-589.

[15] A. Takamasa, and S. Nakai, Contamination introduced during rock sample powdering: Effects from different mill materials on trace element contamination, Geochem. J., 43 (2008) 389-394.

[16] A.A. Shulzhenko, M.P. Bezhenar, and S.A. Bozhko, $\mathrm{cBN} \rightarrow \mathrm{hBN}$ phase transformation during sintering of $\mathrm{cBN}$ and $\mathrm{Al}$ powders at high pressures and temperatures, J. Wide Bandgap Mater. 10:1 (2002) 5-13.

[17] T.M. Usselman, Experimental approach to the state of the core: Part I. The liquidus relations of the Fe-rich portion fo the Fe-Ni-S system from 30 to 100kb. Amer. J. Sci. 275 (1975) 278-290.

[18] J. Ganguly, and G.C. Kennedy, Solubility of K in Fe-S liquid, silicate-K-(Fe-S $)^{\text {Liq }}$ equilibria, and their planetary implications, Earth Planet. Sci. Lett. 35 (1977) 411-420.

[19] R. F. Wedlandt, J. S. Huebner, and W. J Harrison, The redox potential of boron nitride and implications for its use as a crucible material in experimental petrology, Amer. Mineralog. 67 (1982) 170-174.

[20] B. Chen, L. Gao, K. Leinenweber, Y. Wang, T. Sanehira, and J. Li, In situ investigation of high pressure melting behavior in the Fe-S system using synchrotron X-ray radiography, High Press. Res. 28:3 (2008) 315-326. 
[21] J, Qian, D. Mukhopadhyay, K.D. Nguyen, and Y. Ma, Sintering of polycrystalline boron nitride composites for in situ synchrotron high pressure research, Int J Refract Metals Hard Mater. 49 (2015) 288-291.

[22] R.S. Mishra, and A.K. Mukherjee, Processing of high hardness-high toughness alumina matrix nanocomposites, Mater. Sci. Eng. A 301 (2001) 97-101.

[23] H.M. Rietveld, A profile refinement method for nuclear and magnetic structures, J. Appl. Crystallogr. 2 (1969) 65-71.

[24] D. Marioli, C. Narduzzi, C. Offelli, D. Petri, E. Sardini, A. Taroni, Digital time of flight measurement for ultrasonic sensors. Instrumentation and Measurement Technology Conference, Instrumentation and Measurement Technology Conference, IMTC-91. Conference Record, 8th IEEE. (1991) 198-201.

[25] B.J. Zadler, J.H.L. Le Rousseau, J.A. Scales, and M.L. Smith, B.J. Zadler, J.H.L. Le Rousseau, J.A. Scales, and M.L. Smith, Resonant ultrasound spectroscopy: theory and application, Geophys. J. Int. 156 (2004) 154-169.

[26] G. Breit, and E. Wigner, Capture of slow neutrons, Phys. Rev. 49 (1936) 519-531.

[27] A. Migliori, J.L. Sarrao, Resonant Ultrasound Spectroscopy: Applications to Physics, Materials Measurements, and Nondestructive Evaluation, John Wiley \& Sons, Inc., New York, 1997.

[28] W.L. Du Frane, T.G. Sharp, J.L. Mosenfelder, and K. Leinenweber, Ringwoodite growth rates from olivine with 75ppmw H 2 O: Metastable olivine must be nearly anhydrous to exist in the mantle transition zone, Phys. Earth Planet. Inter. 219 (2013) 1-10. 
[29] W.L. Du Frane, and J. A. Tyburczy, Deuterium-hydrogen exchange in olivine: implications for point defects and electrical conductivity, Geosys. Geochem. Geophys. 13:3 (2012) 1-12.

[30] H. Sachdev, R. Haubner, H. Noth, and B. Lux, Investigation of the c-BN/h-BN phase transformation at normal pressure, Diamond. Relat. Mater. 6 (1997) 286-292.

[31] K. Susa, T. Kobayashi, and S. Taniguchi, Catalytic effect of water on the synthesis of cubic BN, Mater. Res. Bull. 9 (1974) 1443-1446.H.M. Ledbetter, R.P. Reed, Elastic properties of metals and alloys, I. Iron-nickel alloys, J. Phys. Chem. Ref. Data 2:3 (1973) 531-617. 
Table 1. Summary of run conditions and results.

\begin{tabular}{|c|c|c|c|c|c|c|c|c|c|c|c|c|c|c|}
\hline Run & $\begin{array}{c}\mathrm{P} \\
(\mathrm{GPa})\end{array}$ & $\begin{array}{c}\mathrm{T} \\
\left({ }^{\circ} \mathrm{C}\right)\end{array}$ & $\begin{array}{c}\text { c-BN } \\
\text { size } \\
(\mu \mathrm{m})\end{array}$ & $\begin{array}{l}\mathrm{c}-\mathrm{BN} \\
(\mathrm{vol} \%)\end{array}$ & $\begin{array}{l}\text { h-BN } \\
\text { (vol\%) }\end{array}$ & $\begin{array}{r}\mathrm{Li}_{2} \mathrm{~B}_{4} \mathrm{O}_{7} \\
(\mathrm{vol} \%)\end{array}$ & $\begin{array}{l}\text { Start } \\
\text { TMD } \\
(\mathrm{g} / \mathrm{cc})\end{array}$ & $\begin{array}{l}\text { End } \\
\text { TMD } \\
(\mathrm{g} / \mathrm{cc})\end{array}$ & $\begin{array}{c}\text { Density } \\
(\mathrm{g} / \mathrm{cc})\end{array}$ & $\begin{array}{l}\text { Error } \\
(\mathrm{g} / \mathrm{cc})\end{array}$ & $v$ & $\begin{array}{c}\mathbf{S} \\
(\mathrm{GPa})\end{array}$ & $\begin{array}{c}\mathbf{E} \\
(\mathrm{GPa})\end{array}$ & $\begin{array}{c}\text { B } \\
(\mathrm{GPa})\end{array}$ \\
\hline \multicolumn{15}{|c|}{ Method 1 runs. } \\
\hline PC3 & 1 & 1300 & $30-40$ & 70.0 & 30.0 & 0.0 & 3.04 & 3.06 & 2.87 & 0.11 & -0.092 & 35 & 66 & 19 \\
\hline PC4 & 1 & 1300 & Mix 1 & 70.0 & 30.0 & 0.0 & 3.04 & 2.69 & 2.78 & 0.04 & 0.051 & 53 & 111 & 41 \\
\hline PC5 & 1 & 1300 & Mix 1 & 65.6 & 28.1 & 6.3 & 3.00 & 2.51 & 2.66 & 0.10 & -0.098 & 52 & 92 & 26 \\
\hline PC6 & 1 & 1300 & $0-2$ & 65.6 & 28.1 & 6.3 & 3.00 & 2.36 & 2.45 & $\mathrm{n} / \mathrm{a}$ & $\mathrm{n} / \mathrm{a}$ & $\mathrm{n} / \mathrm{a}$ & $\mathrm{n} / \mathrm{a}$ & $\mathrm{n} / \mathrm{a}$ \\
\hline PC7 & 1 & 1300 & $0-2$ & 70.0 & 30.0 & 0.0 & 3.04 & 2.85 & 2.76 & 0.04 & 0.112 & 44 & 99 & 43 \\
\hline PC8 & 1 & 1300 & $0-2$ & 66.4 & 28.5 & 5.1 & 3.01 & 2.70 & 2.65 & 0.09 & 0.142 & 55 & 123 & 57 \\
\hline $\mathrm{PC} 10$ & 1 & 1300 & Mix 1 & 66.5 & 28.5 & $5.0 *$ & 3.01 & 2.55 & 2.56 & 0.05 & 0.124 & 41 & 92 & 41 \\
\hline \multicolumn{15}{|c|}{ Method 2 runs. } \\
\hline PC13 & 1 & 1300 & $30-40$ & 70.0 & 30.0 & 0.0 & 3.04 & 3.05 & 2.97 & 0.04 & -0.424 & 30 & 34 & 6 \\
\hline $\mathrm{PC} 14$ & 1 & 1300 & $30-40$ & 66.4 & 28.5 & 5.1 & 3.01 & 3.00 & 2.86 & 0.06 & 0.134 & 84 & 192 & 88 \\
\hline PC15 & 1 & 1300 & Mix 2 & 69.9 & 25.0 & 5.1 & 3.06 & 3.05 & 3.01 & 0.03 & 0.118 & 123 & 271 & 118 \\
\hline PC16 & 1 & 1300 & Mix 2 & 75.0 & 25.0 & 0.0 & 3.11 & 3.11 & 3.06 & 0.05 & 0.101 & 109 & 238 & 100 \\
\hline PC18 & 1 & 1300 & Mix 2 & 79.9 & 15.0 & 5.1 & 3.19 & 3.14 & 3.11 & 0.04 & 0.126 & 126 & 285 & 127 \\
\hline \multirow[t]{2}{*}{ PC19 } & 1 & 1200 & Mix 2 & 69.9 & 25.0 & 5.1 & 3.06 & 3.07 & 3.07 & 0.03 & 0.259 & 139 & 351 & 243 \\
\hline & & & & & & & & & & & 0.135 & 121 & 274 & 125 \\
\hline \multirow[t]{2}{*}{ PC20 } & 1 & 1200 & Mix 2 & 75.0 & 25.0 & 0.0 & 3.11 & 3.12 & 3.14 & 0.04 & 0.124 & 119 & 267 & 119 \\
\hline & & & & & & & & & & & 0.124 & 128 & 287 & 127 \\
\hline \multirow[t]{2}{*}{ PC21 } & 1 & 1200 & Mix 2 & 74.9 & 20.0 & 5.1 & 3.13 & 3.17 & 3.11 & 0.05 & 0.137 & 144 & 326 & 150 \\
\hline & & & & & & & & & & & 0.154 & 143 & 331 & 159 \\
\hline \multirow[t]{2}{*}{$\mathrm{PC} 22$} & 1 & 1200 & Mix 2 & 79.9 & 15.0 & 5.1 & 3.19 & 3.21 & 3.13 & 0.03 & 0.126 & 155 & 348 & 155 \\
\hline & & & & & & & & & & & 0.154 & 143 & 331 & 159 \\
\hline PC23 & 1 & 1100 & Mix 2 & 69.9 & 25.0 & 5.1 & 3.06 & 3.05 & 3.05 & 0.04 & 0.118 & 127 & 284 & 124 \\
\hline PC24 & 1 & 1100 & Mix 2 & 75.0 & 25.0 & 0.0 & 3.11 & 3.17 & 3.07 & 0.03 & 0.082 & 103 & 220 & 88 \\
\hline PC25 & 1 & 1100 & Mix 2 & 74.9 & 20.0 & 5.1 & 3.13 & 3.17 & 3.12 & 0.03 & $\mathrm{n} / \mathrm{a}$ & $\mathrm{n} / \mathrm{a}$ & $\mathrm{n} / \mathrm{a}$ & $\mathrm{n} / \mathrm{a}$ \\
\hline PC26 & 1 & 1100 & Mix 2 & 79.9 & 15.0 & 5.1 & 3.19 & 3.22 & 3.14 & 0.04 & 0.163 & 130 & 335 & 166 \\
\hline $\mathrm{PC} 27$ & 1 & 1000 & Mix 2 & 69.9 & 25.0 & 5.1 & 3.06 & 3.11 & 3.08 & 0.07 & 0.102 & 125 & 275 & 115 \\
\hline PC28 & 1 & 1000 & Mix 2 & 75.0 & 25.0 & 0.0 & 3.11 & 3.16 & 3.07 & 0.07 & $\mathrm{n} / \mathrm{a}$ & $\mathrm{n} / \mathrm{a}$ & $\mathrm{n} / \mathrm{a}$ & $\mathrm{n} / \mathrm{a}$ \\
\hline PC29 & 1 & 1000 & Mix 2 & 74.9 & 20.0 & 5.1 & 3.13 & 3.19 & 3.10 & 0.04 & 0.133 & 131 & 296 & 135 \\
\hline PC39 & 1 & 900 & Mix 2 & 69.9 & 25.0 & 5.1 & 3.06 & 2.97 & 2.99 & 0.10 & 0.069 & 119 & 254 & 98 \\
\hline PC32 & 1 & 900 & Mix 2 & 75.0 & 25.0 & 0.0 & 3.11 & 3.10 & 3.01 & 0.07 & 0.125 & 105 & 245 & 109 \\
\hline PC33 & 1 & 900 & Mix 2 & 74.9 & 20.0 & 5.1 & 3.13 & 3.13 & 3.05 & 0.05 & 0.182 & 154 & 251 & 131 \\
\hline PC34 & 1 & 900 & Mix 2 & 79.9 & 15.0 & 5.1 & 3.19 & 3.09 & 3.06 & 0.08 & 0.075 & 161 & 342 & 134 \\
\hline PC41 & 0.5 & 1300 & Mix 2 & 74.9 & 20.0 & 5.1 & 3.13 & 3.08 & 2.93 & 0.03 & 0.151 & 88 & 201 & 96 \\
\hline \multirow[t]{2}{*}{ PC40 } & 0.5 & 1200 & Mix 2 & 69.9 & 25.0 & 5.1 & 3.06 & 3.04 & 3.00 & 0.03 & 0.116 & 103 & 229 & 100 \\
\hline & & & & & & & & & & & 0.152 & 108 & 250 & 120 \\
\hline PC36 & 0.5 & 1200 & Mix 2 & 75.0 & 25.0 & 0.0 & 3.11 & 3.12 & 3.05 & 0.03 & 0.131 & 100 & 226 & 102 \\
\hline PC37 & 0.5 & 1200 & Mix 2 & 74.9 & 20.0 & 5.1 & 3.13 & 3.12 & 2.97 & 0.04 & 0.171 & 88 & 219 & 111 \\
\hline PC38 & 0.5 & 1200 & Mix 2 & 79.9 & 15.0 & 5.1 & 3.19 & 3.16 & 3.03 & 0.03 & $\mathrm{n} / \mathrm{a}$ & $\mathrm{n} / \mathrm{a}$ & $\mathrm{n} / \mathrm{a}$ & $\mathrm{n} / \mathrm{a}$ \\
\hline $\mathrm{PC} 42$ & 0.5 & 1100 & Mix 2 & 74.9 & 20.0 & 5.1 & 3.13 & 3.15 & 2.94 & 0.03 & 0.147 & 102 & 234 & 110 \\
\hline \multirow[t]{2}{*}{ PC55 } & 0.5 & 1000 & Mix2 & 69.9 & 25.0 & 5.1 & 3.06 & 3.11 & 3.08 & 0.04 & -0.034 & 96 & 185 & 58 \\
\hline & & & & & & & & & & & 0.182 & 92 & 218 & 114 \\
\hline \multirow[t]{2}{*}{ PC56 } & 0.5 & 1000 & Mix2 & 75.0 & 25.0 & 0.0 & 3.11 & 3.15 & 3.06 & 0.04 & 0.076 & 79 & 170 & 67 \\
\hline & & & & & & & & & & & 0.099 & 94 & 206 & 86 \\
\hline \multirow[t]{2}{*}{ PC57 } & 0.5 & 1000 & Mix2 & 75.0 & 20.0 & 5.0 & 3.13 & 3.15 & 3.04 & 0.03 & -0.013 & 111 & 220 & 71 \\
\hline & & & & & & & & & & & 0.079 & 117 & 252 & 100 \\
\hline PC58 & 0.5 & 1000 & Mix2 & 79.9 & 15.0 & 5.1 & 3.19 & 3.20 & 3.08 & 0.04 & 0.133 & 138 & 312 & 142 \\
\hline PC43 & 0.5 & 900 & Mix 2 & 74.9 & 20.0 & 5.1 & 3.13 & 3.12 & 3.01 & 0.03 & -0.010 & 94 & 187 & 61 \\
\hline
\end{tabular}

Mix 1 is 1:1 parts $0-2 \mu \mathrm{m}(\mathrm{DI})$ and $30-40 \mu \mathrm{m}$ (DI).

Mix 2 is 1:4 parts 2-4 $\mu \mathrm{m}$ (Engis) and 30-40 $\mu \mathrm{m}$ (DI).

Start TMD (theoretical mass density) is calculated from Entries in bold had $v<0$ or $v<0.2$ using time of flight method.

Entries in italics were measured using resonance metho individual powder weights.

End TMD adjusts for the post-run $\mathrm{cBN}$ : $\mathrm{hBN}$ wt. ratio measured by XRD.

* $\mathrm{B}_{2} \mathrm{O}_{3}$ used in run PC10 instead of $\mathrm{Li}_{2} \mathrm{~B}_{4} \mathrm{O}_{7}$. 


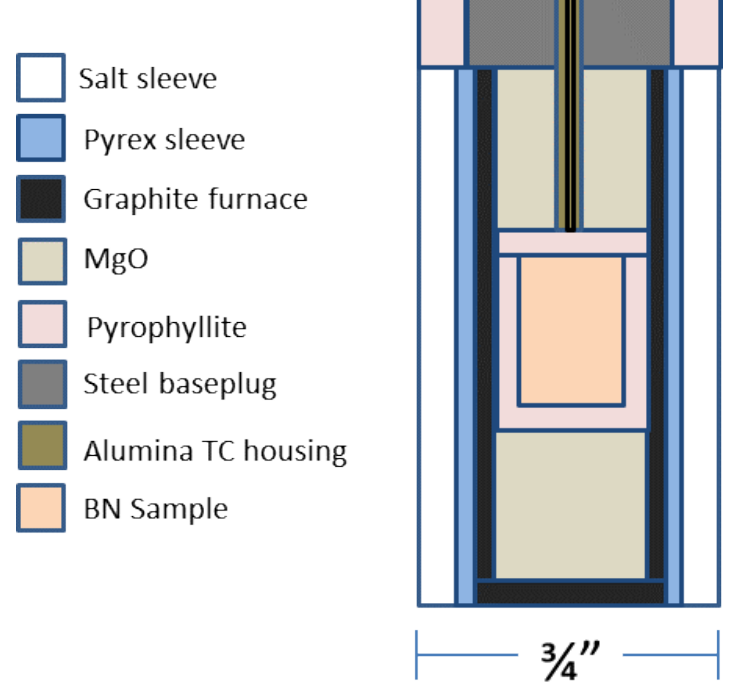

Fig. 1. Cross-sectional schematic of the piston cylinder assembly and materials.

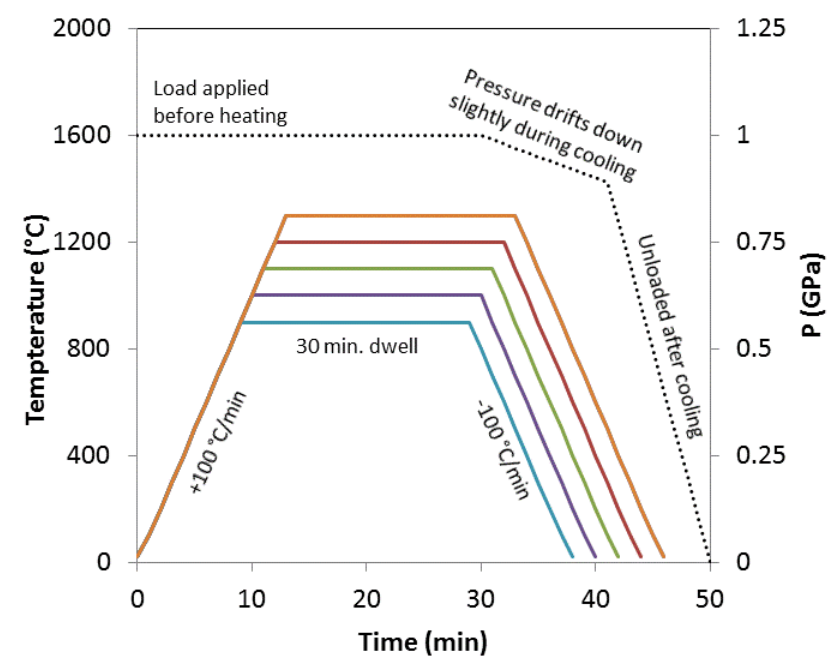

Fig. 2. Plot of typical temperature/ pressure path followed for piston cylinder runs at 1.0 GPa.

Similar pressure path was followed for runs at $0.5 \mathrm{GPa}$. 

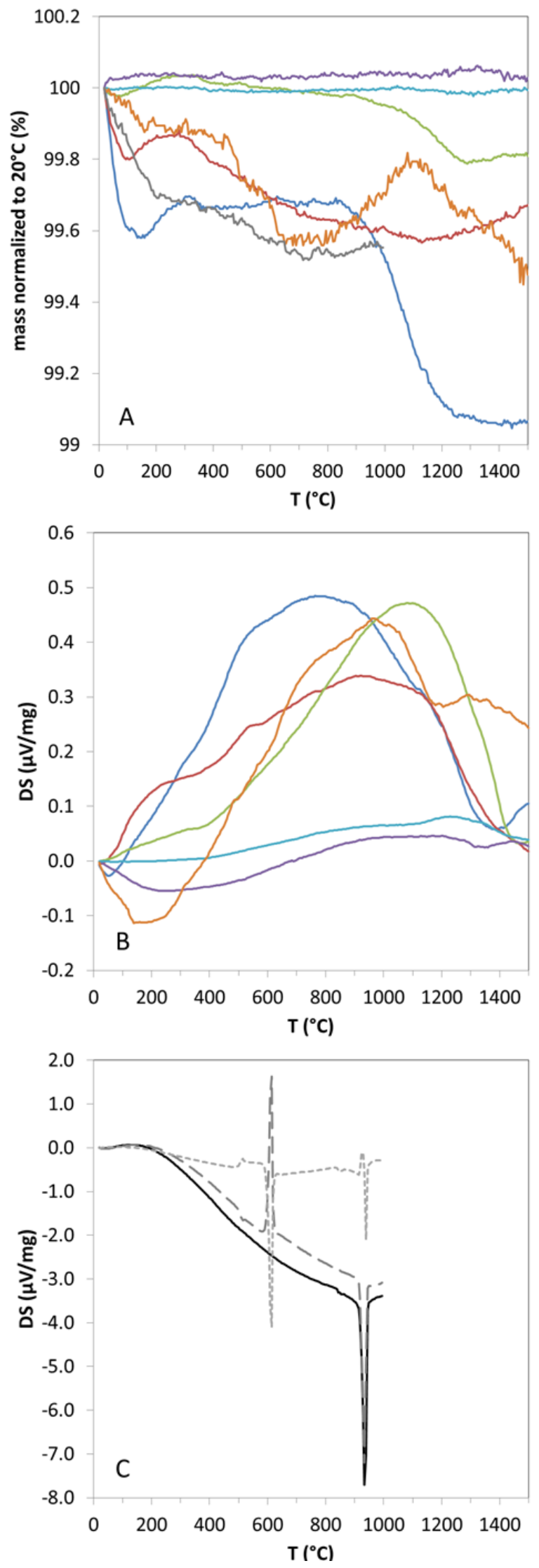
Fig. 3. TGA (A) and DSC (B) data as a function of temperature (with rerun subtracted as a baseline) on the constituent powders used in this study. Data for $\mathrm{cBN}$ is shown as a function of particle size: 0-0.5 $\mu \mathrm{m}$ - blue, 0-2 $\mu \mathrm{m}$ - red, 2-4 $\mu \mathrm{m}$ - green, 30-40 $\mu \mathrm{m}$ - purple, $35-45 \mu \mathrm{m}-$ turquoise. $\mathrm{hBN}$ is shown in orange. TGA data for LTB is shown in grey. DSC data for LTB (C) is shown as a solid black line for the first measurement, a dark grey long-dashed line for the second measurement, and with the rerun subtracted in a light grey short-dashed line. 

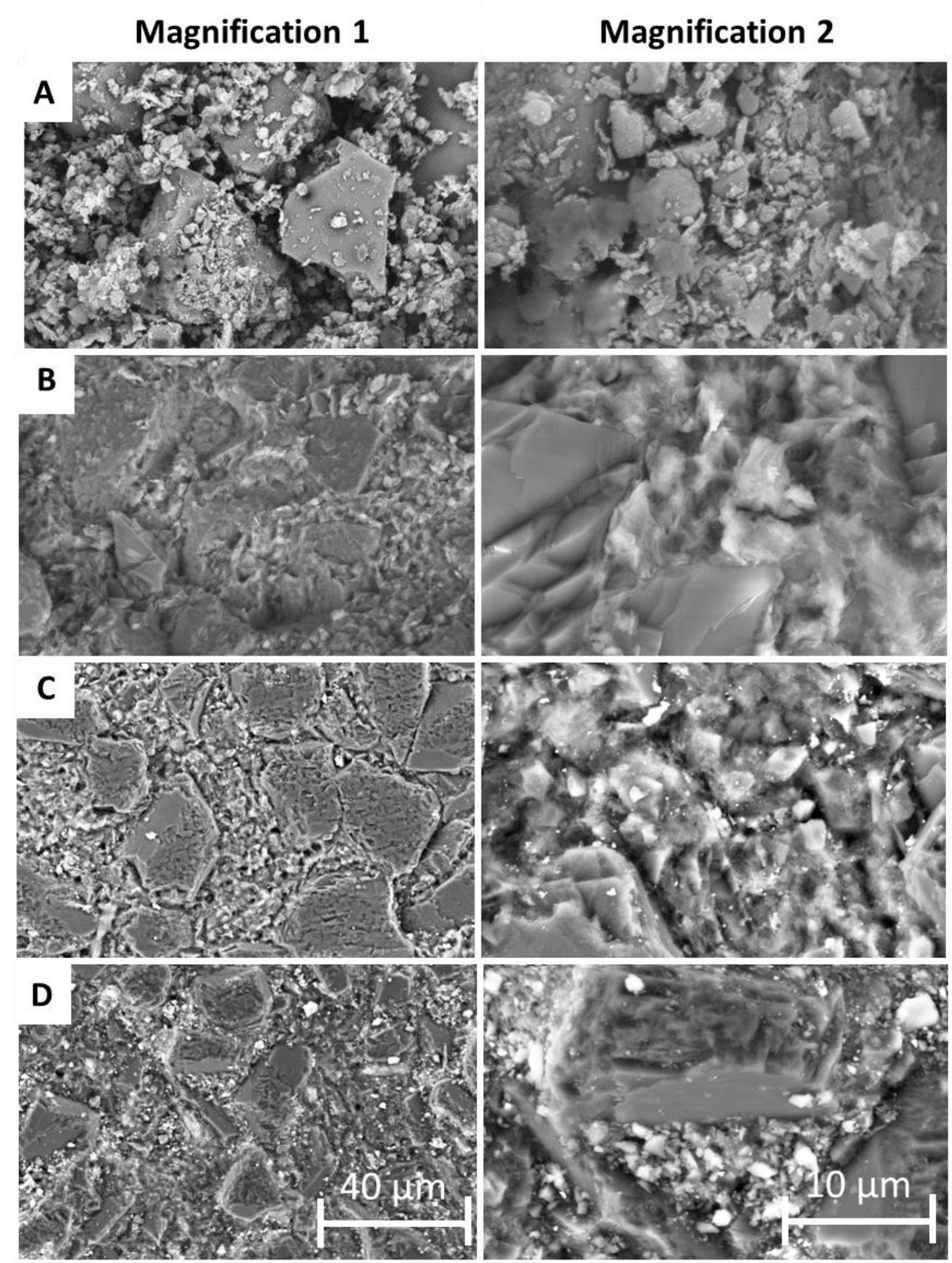

Fig. 4. SEM images at two different magnifications of A) an unconsolidated sample powder mixture; B) a freshly fractured surface and C) a polished surface of a sample consolidated at 1 GPa (PC19); and D) a polished surface of a sample consolidated at $0.5 \mathrm{GPa}$ (PC40). 


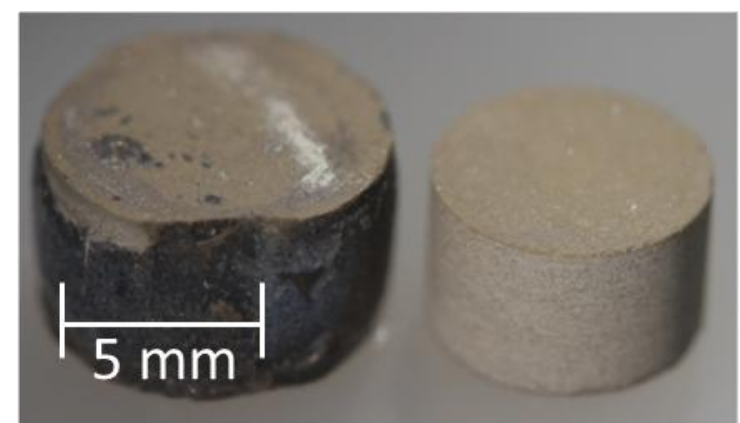

Fig. 5. Picture of samples PC35 (left) and PC29 (right). Both samples had their top and bottom surfaces ground off. PC29 was turned down into a cylinder on a lathe in order to simplify geometry into a cylinder, allowing for precise measurements of volume and density. 

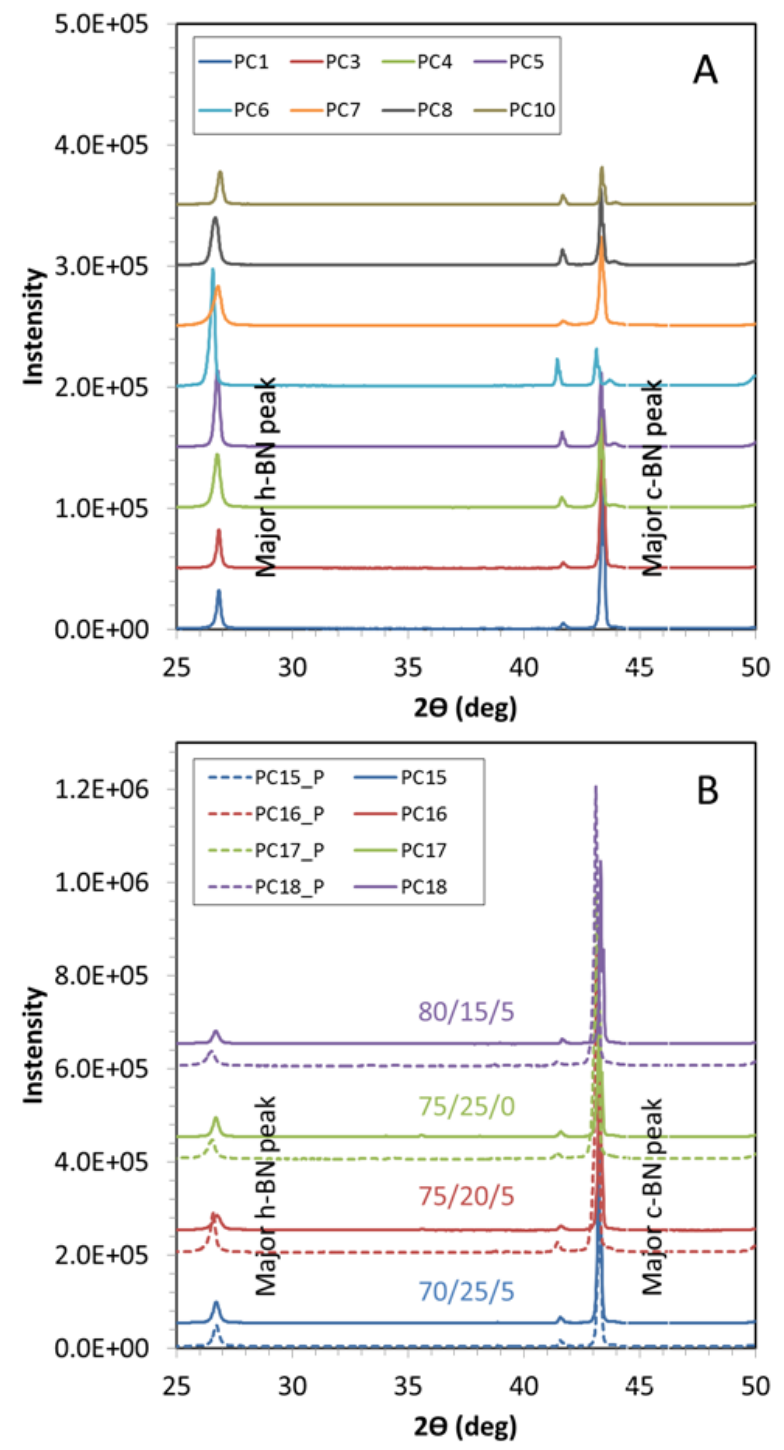

Fig 6. A) A comparison of XRD spectra collected samples post-run using method 1 prior.

Variable amounts of $\mathrm{cBN}$ transformed into $\mathrm{hBN}$ during these preliminary runs. B) XRD spectra collected on samples using method 2 detected little to no $\mathrm{cBN}$ to $\mathrm{hBN}$ phase transformation. XRD spectra for runs PC15 (blue), PC16 (red), PC17 (green), and PC18 (purple) were similar for pre-run powder mixtures (dashed line) and post-run samples (solid line), indicating that little to no $\mathrm{cBN}$ to $\mathrm{hBN}$ phase transformation occurred in runs as high as $1300{ }^{\circ} \mathrm{C}$. Spectra are arbitrarily offset in intensity for ease of visualization. 

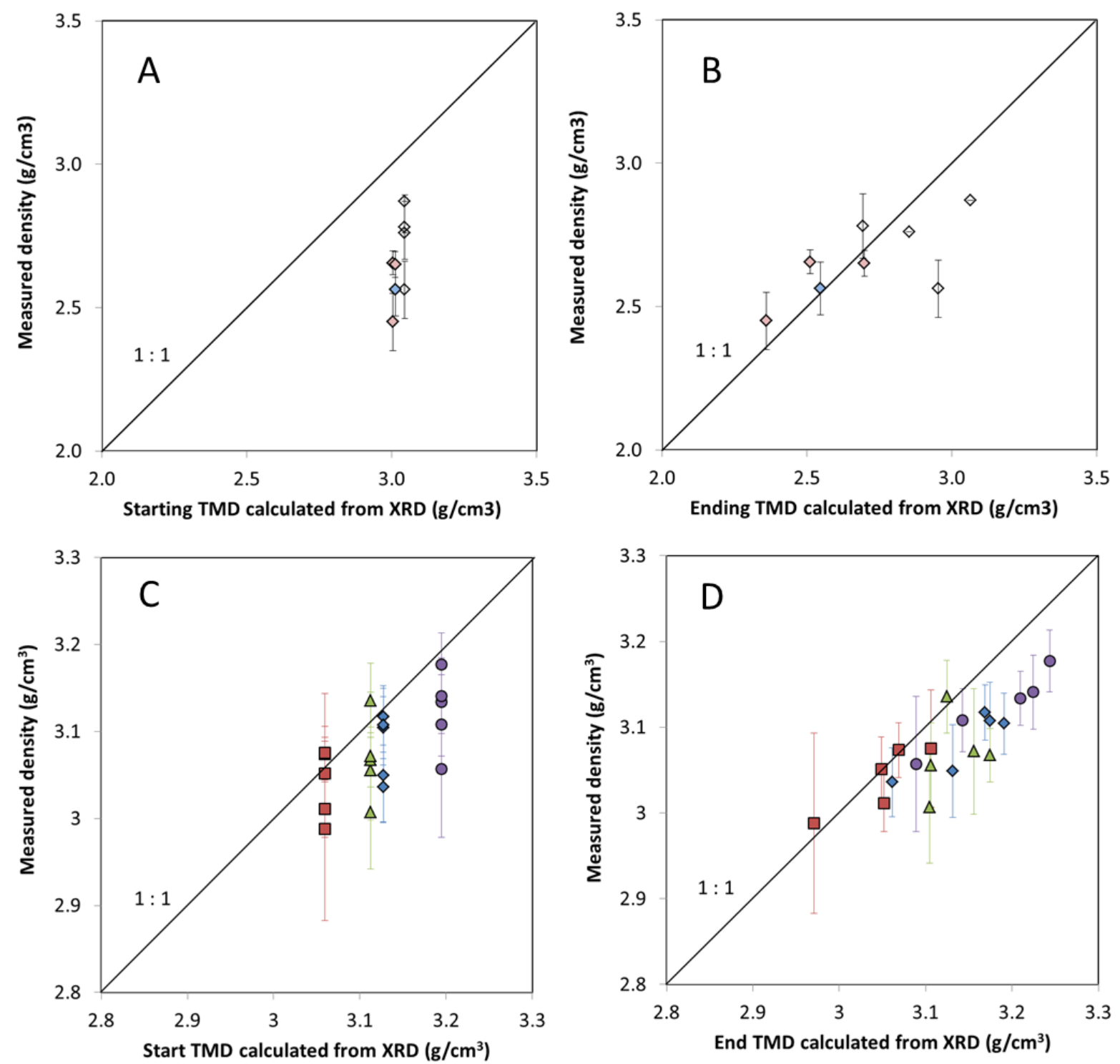

Fig. 7. Comparisons of measured density to starting and ending theoretical mass density (TMD) TMD for runs at $1 \mathrm{GPa}$. Starting TMD is calculated with high precision from individual powder weights. End TMD adjusts for the post-run $\mathrm{cBN}$ : $\mathrm{hBN}$ wt. ratio measured by XRD, and has \pm $0.07 \mathrm{~g} / \mathrm{cm}^{3}$ error. A, B) Method 1 runs are shown for those without binder are as open symbols, with LTB as pink symbols, with $\mathrm{B}_{2} \mathrm{O}_{3}$ as a blue symbol. B, D) Method 2 runs are shown for samples with the following cBN/hBN/LTB vol\% ratios: 70/20/5 as red squares, $75 / 20 / 5$ as blue diamonds, 75/25/0 as green triangles, and as 80/15/5 purple circles. 

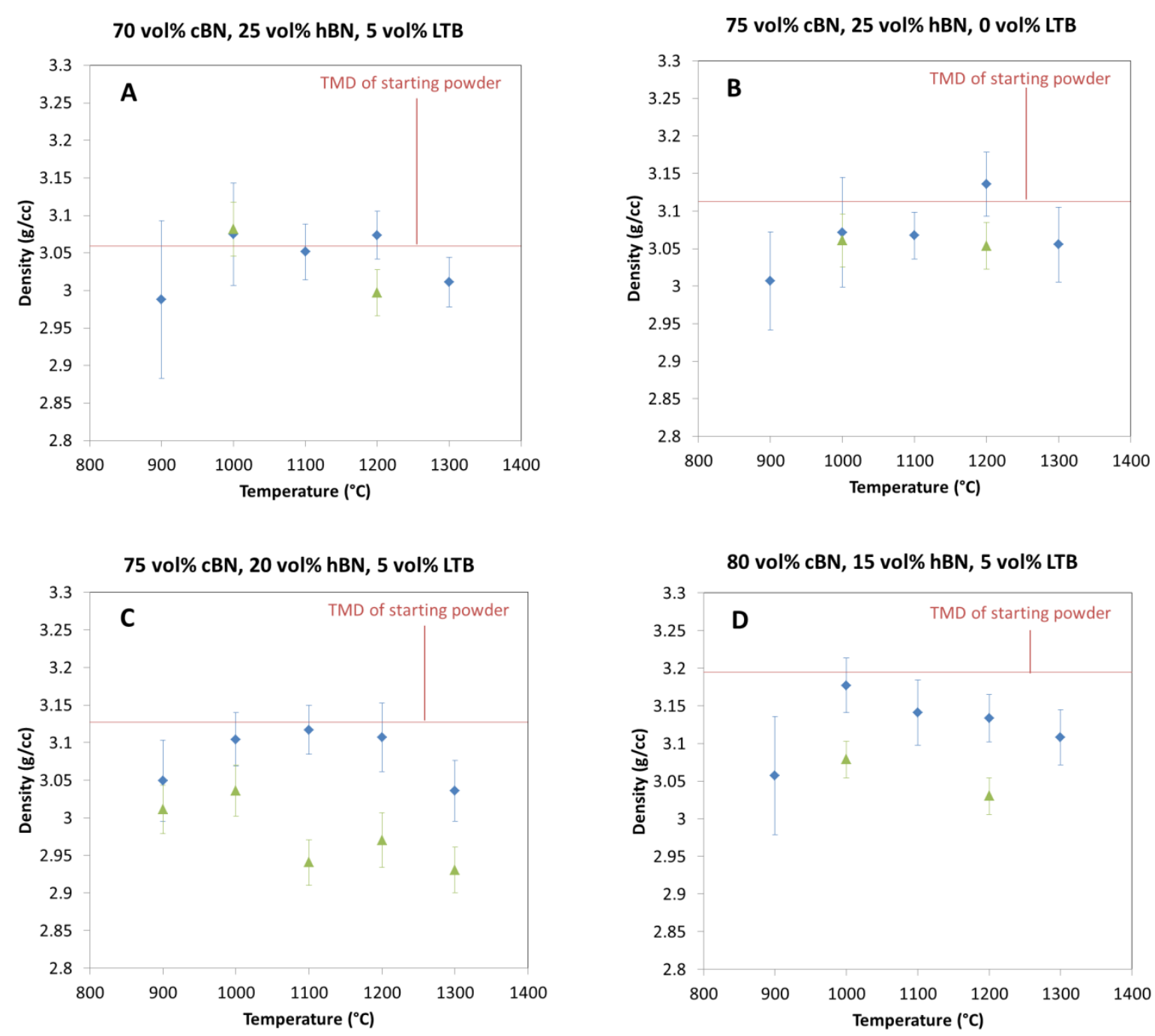

Fig. 8. Resulting sample densities as a function of temperature and pressure for samples that varied in the vol\% of cBN/hBN/LTB as follows: A) $75 / 20 / 5$, B) $75 / 25 / 0$, C) $70 / 25 / 5$, and D) 80/15/5. Blue diamonds indicate runs at $1.0 \mathrm{GPa}$, and green triangles indicate runs at $0.5 \mathrm{GPa}$. 

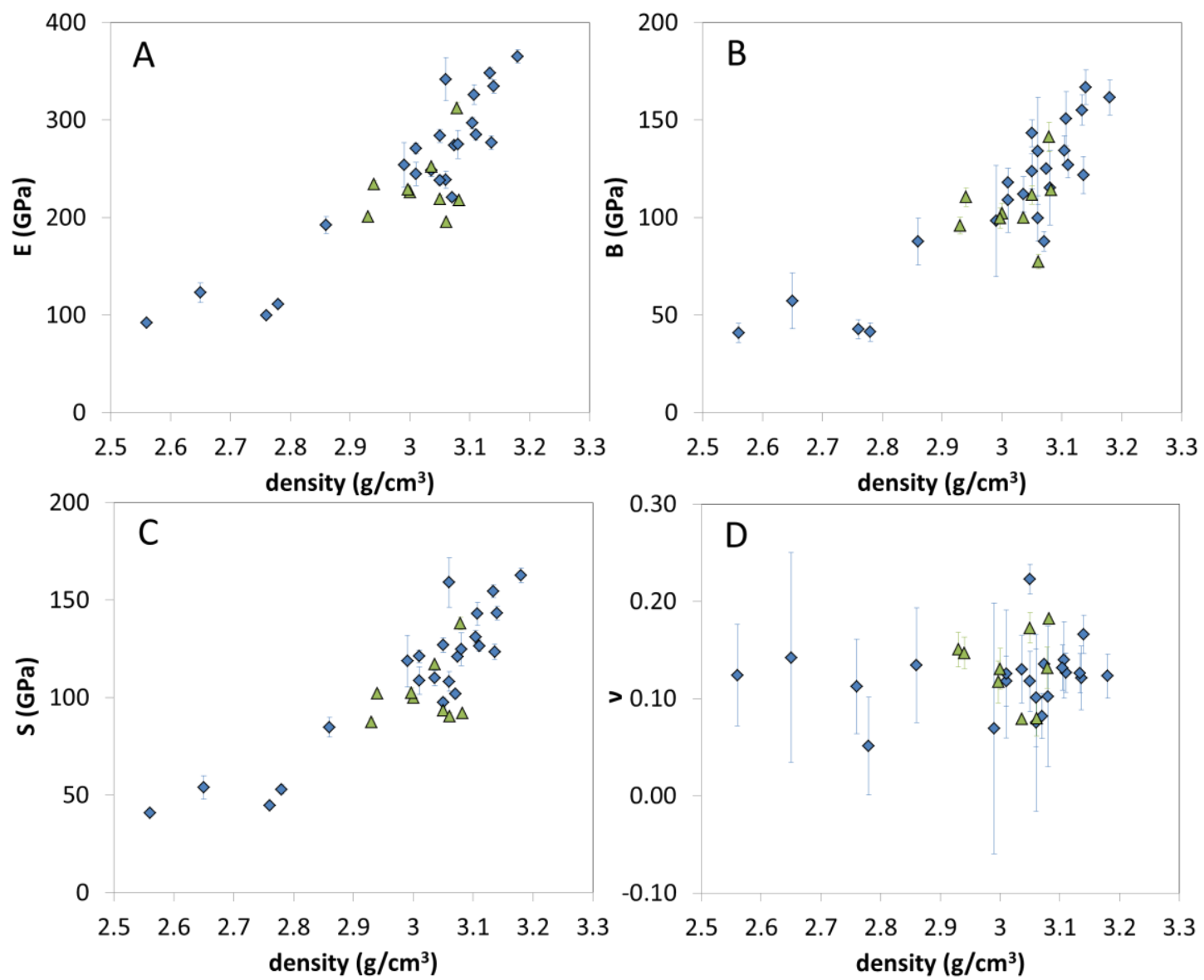

Fig. 9. Ultrasonic measurements of A) Young's modulus, B) bulk modulus, C) shear modulus, and D) Poisson's ratio as a function of density. Samples are shown as blue diamonds for those pressed at $1 \mathrm{GPa}$, and green triangles for those pressed at $0.5 \mathrm{GPa}$. Most data shown was obtained using the TOF method. RUS data were plotted for samples that had Poisson's ratios between 0 to 0.25 using TOF method (See Table 1 for complete data set). 

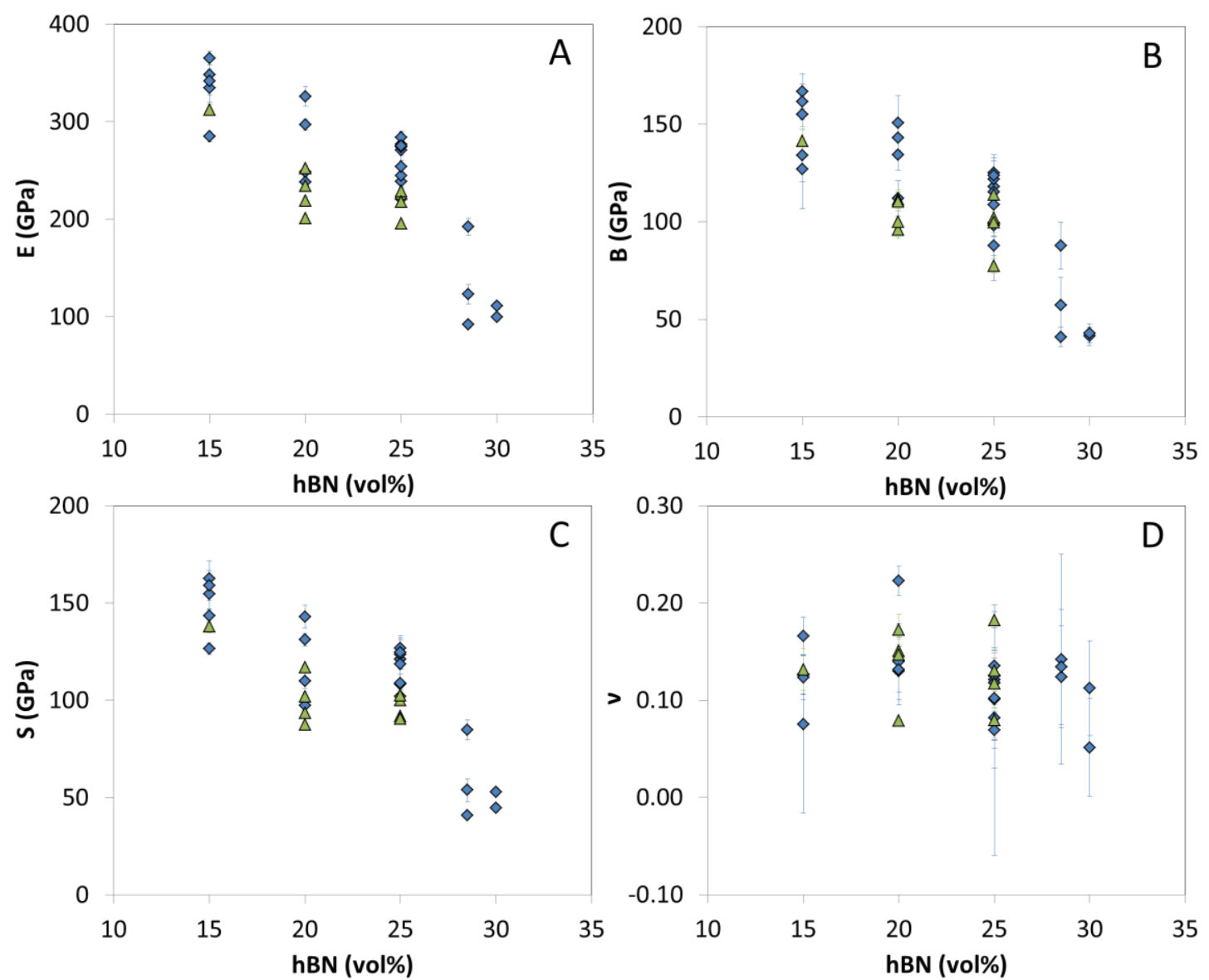

Fig. 10. Ultrasonic measurements of A) Young's modulus, B) bulk modulus, C) shear modulus, and D) Poisson's ratio as a function of h-BN volume percent. Samples are shown as blue diamonds for those pressed at $1 \mathrm{GPa}$, and green triangles for those pressed at $0.5 \mathrm{GPa}$. Most data shown was obtained using the TOF method. RUS data were plotted for samples that had Poisson's ratios between 0 to 0.25 using TOF method (See Table 1 for complete data set). 
